\title{
Presence of fibronectin in pneumoconiotic lesions
}

\author{
JC WAGNER, J BURNS, DE MUNDAY, JO'D MCGEE
}

From the Pneumoconiosis Unit, Medical Research Council, Llandough Hospital, Penarth, South Glamorgan, and the University of Oxford, Nuffield Department of Pathology, John Radcliffe Hospital, Oxford

ABSTRACT During the last 10 years our investigations have confirmed that collagen is not the major protein material in the lesions of progressive massive fibrosis of coal workers. ${ }^{1}$ In previous studies it was demonstrated that a substance similar in composition to fibrin was an important component in these masses. We report immunohistochemical studies on the lungs of seven coalworkers which show that the complex extracellular material in six of the lesions of massive fibrosis contains fibronectin. Preliminary observations indicate that fibronectin is also present in the lesions of silicosis and asbestosis.

Fibronectin ${ }^{2}$ is a dimeric glycoprotein with a molecular weight of 450000 daltons. Two forms have been characterised, a soluble form present in plasma and other extracellular body fluids, originally isolated by Morrison et al in $1948^{3}$ and called "cold-insoluble globulin", and a form associated with the cell surface of a number of cultured cell lines, also known as "large external transformation sensitive protein" (LETS). In vitro studies suggest that fibronectin is important in adhesion of cell to cell and cell to substratum. It binds specifically to fibrinogen and fibrin, collagen, and heparin. Fibronectin is a component of reticulin "which is the descriptive name for fibres blackened by silver impregnation". 4

Fibronectin is produced by fibroblasts and macrophages, including those occurring in the alveoli..$^{5}$ Therefore it would appear that fibronectin probably occurred in the development of the early lesions of the common forms of the pneumoconioses. The histological features of these lesions have been summarised. ${ }^{6}$ The initial lesions of asbestosis are accumulations of macrophages, asbestos bodies and fibres in the alveoli arising directly from the respiratory bronchioles; these accumulations become organised with the appearance of a network of reticulin fibres. In a similar manner the earliest lesions in coal workers pneumoconiosis are deposits of dust containing macrophages in similar alveolar spaces gradually held in position by reticulin fibres,

Address for reprint requests: Dr JC Wagner, MRC Pneumoconiosis Unit, Llandough Hospital, Penarth, Glamorgan CF6 1XX. which later may expand into the stellate lesions of deeply pigmented dust reticulination. In silicosis, the foci of perivascular dust reticulination develop around the blood vessels at the level of the respiratory bronchioles. In all three situations it is possible that fibronectin may, by its adhesive properties, hold the cells and dusts in these alveoli and then play a part in the formation of the reticulin network and later a role in the formation of the foci of dust reticulination and the subsequent collagenisation.

At the other end of the spectrum of the pneumoconioses, the possibility of fibronectin occurring in the massive lesions must be considered. In the previous study of the massive lesions in the lungs of coal workers, the actual protein or proteins accompanying the collagen were not readily characterised. Computation of the amino acid composition of this material most nearly resembled fibrin, but this was not identical. An attempt to carry out a similar analysis of the massive lesions seen in the lungs of North Wales slate workers produced an even more complex result than the study on the coal workers, but the collagen once again accounted for less than a third of the protein content of the lesions and fibrouslike material was the major protein component (Wusteman F, personal communication).

A limited amount of the reagents required for the histochemical demonstration was available. It was decided, therefore, to undertake a preliminary study in which as wide a range of pneumoconiotic lesions as possible could be covered. From this study we hoped to obtain information as to whether further more detailed investigations would be justified. 


\section{Methods}

We had planned to use fixed processed tissue for these studies which would have allowed us to study precise disease patterns. Unfortunately our first attempts at using sections from these selected blocks failed and, in view of the small amounts of reagents left, we decided to rely on fresh tissue. Urgent requests for help in collecting material were made to a number of colleagues, and with their cooperation we were able to proceed with this investigation. However, no suitable fresh tissue from a case of silicosis became available, so we had to use fixed tissue from one such patient with greater success than in the original attempt. We received lung tissue from one case of severe asbestosis and from seven cases of coal worker's pneumoconiosis with massive fibrosis. These were selected for showing evidence of activity with the exception of one case in which the lesions were found to be small sclerotic fibrous nodules, not surrounded by dust reticulination.

Cryostat sections of the "snap" frozen material from the coal workers and asbestos cases were cut at $5 \mu \mathrm{m}$. These sections were fixed in acetone at $-20^{\circ} \mathrm{C}$ for 15 minutes, followed by a wash in $\mathrm{pH} \mathrm{7.6}$ phosphate buffered saline (PBS). Subsequently, sections were exposed to rabbit anti-fibronectin $1: 30 .^{\text {? }}$ Rabbit anti-fibronectin absorbed with fibronectin or normal rabbit serum diluted 1:30 acted as controls. After washing in PBS the sections were treated with swine anti-rabbit IgG labelled with peroxidase (Dakopatts, Mercia Brocades Ltd). After a further wash in PBS, sites of peroxidase binding were revealed by treatment with hydrogen peroxide and $3: 3^{\prime}$ diaminobenzidine tetrahydrochloride.

Paraffin sections of formalin-fixed tissue from the case of silicosis were dewaxed and digested with pepsin $0.4 \%$ in 0.01 normal $\mathrm{HCl}$ or protease $0.1 \%$ in PBS to reveal antigen as described elsewhere. ${ }^{78}$ Sections were then treated with antisera as already described.

\section{Results}

In six of the seven coalworkers' lungs there was clear evidence of an increase in fibronectin in the large lesions (figure) and in the surrounding dust reticulination. The one case in which there was no increase in fibronectin was that with the acellular fibrotic nodular lesions. This increase in fibronectin was diffuse and it was not possible to demonstrate any precise localisation. In the sections taken from the case of asbestosis, there was increased staining for fibronectin in the areas of interstitial fibrosis, as well as in the lesions of the organising bronchopneumonia which was present. In a preliminary attempt

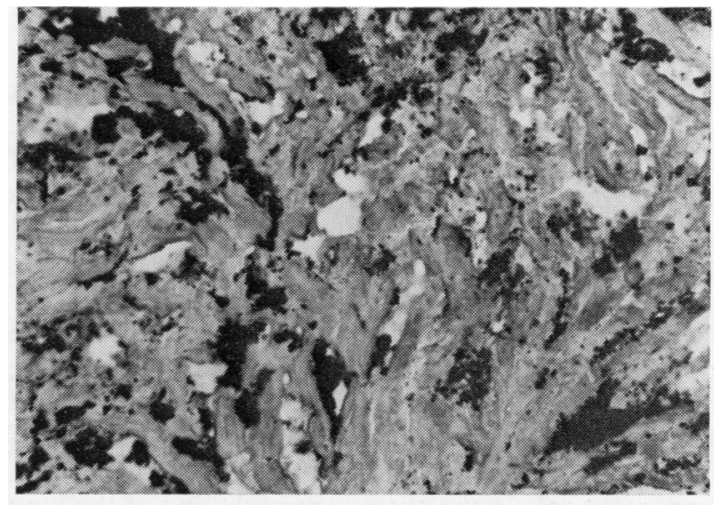

(a)

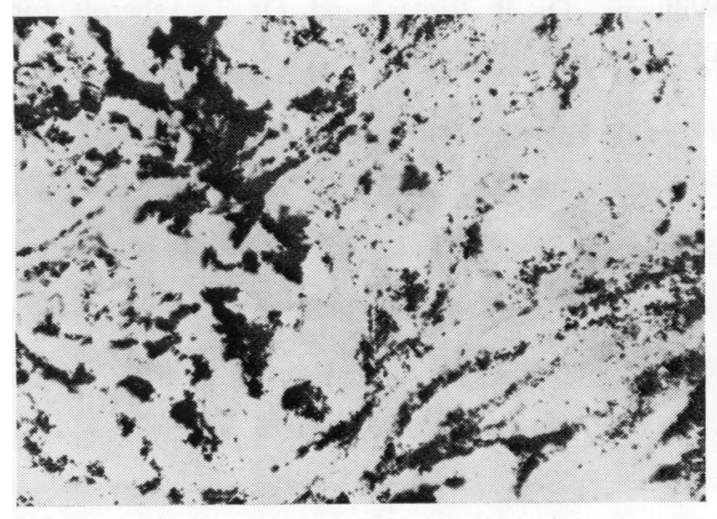

(b)

Figure (a) Central zone from area of massive fibrosis showing increased staining for fibronectin. Frozen section treated with rabbit anti-fibronectin IgG and peroxidase labelled swine anti-rabbit IgG. $\times 280$. (b) Similar field from adjacent section treated with fibronectin absorbed rabbit anti-fibronectin IgG and peroxidase labelled swine anti-rabbit IgG. Shows absence of staining. The black material in both $(a)$ and $(b)$ is coal dust. $\times 280$.

on formalin-fixed, paraffin-embedded silicotic lung sections, there was increased staining for fibronectin both in the acellular foci of concentric fibrosis and in the surrounding areas of dust reticulination.

\section{Discussion}

In this preliminary study we have only attempted to demonstrate the presence of fibronectin in the 
lesions. The results justify further studies which will be aimed at both the localisation of the fibronectin and its association with fibrin, fibrinogen, IgG and various types of collagen. Our animal inhalation studies should provide valuable material to enable us to follow the distribution of these proteins as the interstitial fibrosis develops. The ultimate aim of these investigations is to produce information on the pathogenesis of the various forms of interstitial pulmonary fibrosis, particularly the idiopathic variety for which the most regrettable term "cryptogenic fibrosing alveolitis" has been used. The possibility of this broader significance of the finding of fibronectin has been discussed by Rennard and Crystal, , who stated "the increased amount of fibronectin in the alveolar structures may play an important role in the chronic remodelling of the lung parenchyma that is characteristic of these diseases."

We wish to thank Dr RME Seal, Dr W JonesWilliams, Dr R Ryder, and Dr T Ashcroft for presenting us with tissue.

\section{References}

${ }^{1}$ Wagner JC, Wusteman FS, Edwards JH, Hill RJ. The composition of massive lesions in coal miners. Thorax 1975;30:382-8.

2 Dixon AJ, Burns J, Dunnill MS, McGee JO'D. Distribution of fibronectin in normal and diseased human kidneys. J Clin Pathol 1980;33:1021-8.

${ }^{3}$ Morrison PR, Edsall JT, Miller SG. Preparation and properties of serum and plasma proteins XVIII. The separation of purified fibrinogen from fraction 1 of human plasma. J Am Chem Soc 1948;70:3103-8.

4 Stenman S, Vaheri A. Distribution of a major connective tissue protein, fibronectin, in normal human tissues. J Exp Med 1978;147:1054-64.

${ }^{5}$ Rennard SI, Crystal RG. Fibronectin in human bronchopulmonary lavage fluid: elevation in patients with interstitial lung disease. $J$ Clin Invest 1981 ; in press.

- Wagner JC. Pulmonary fibrosis and mineral dusts. Ann Rheum Dis 1977;36:42-6.

7 Burns J, Dixon AJ, Woods JC. Immunoperoxidase localisation of fibronectin in glomeruli of formalin fixed paraffin processed renal tissue. Histochemistry 1980;67: 73-8.

8 Burns J. Immunohistochemical methods and their application in the routine laboratory. In: Anthony PP, Woolf N, eds. Recent advances in histopathology. Tenth edition. Edinburgh, London: Churchill Livingstone, 1978:337-50. 